Article

\title{
Experimental proof of a solar-powered heat pump system for permafrost thermal stabilization
}

\author{
Elizaveta S. Sharaborova ${ }^{1}$, Taisia V. Shepitko ${ }^{2}$ and Egor Y. Loktionov ${ }^{1, *}$ \\ 1 Bauman Moscow State Technical University, 5-1, 2nd Baumanskaya str., Moscow 105005, Russia. \\ 2 Russian University of Transport, 9b9, Obraztsova str., Moscow 127994, Russia. \\ * Correspondence: eloktionov@mail.ru.
}

\begin{abstract}
We have suggested earlier a new sustainable method for permafrost thermal stabilization that combines passive screening of solar radiation and precipitation with active solarpowered cooling of the near-surface soil layer thus preventing heat penetration in depth. Feasibility of this method has been shown by calculations, but needed experimental proof. In this article, we are presenting the results of soil temperature measurements obtained at the experimental implementation of this method outside of the permafrost area which actually meant higher thermal loads than in Polar Regions. We have shown that near-surface soil layer is kept frozen during the whole summer, even at air temperatures exceeding $+30^{\circ} \mathrm{C}$. Therefore, the method has been experimentally proven to be capable of sustaining soil frozen even in more extreme conditions than expected in permafrost areas. In addition to usual building and structure thermal stabilization, the method could be used to prevent the development of thermokarst, gas emission craters, and landslides; greenhouse gases, chemical, and biological pollution from the upper thawing layers at least in the area of human activities; protection against coastal erosion; and permafrost restoration after wildfires. Using commercially widely available components, the technology can be scaled up for virtually any size objects.
\end{abstract}

Keywords: solar energy; geothermal energy; seasonally thawed layer; thermosyphon; heat flux; performance indicator; near-surface layer; heat shielding.

\section{Introduction}

Permafrost is characterized by a subzero temperature of rocks and / or soil for two or more years and the absence of seasonal thawing. Permafrost underlies ca. 35 million $\mathrm{km}^{2}$ of land around the world: throughout Antarctica, about $85 \%$ of Alaska, $65 \%$ of Russia, $55 \%$ of Canada, about a quarter of the Northern Hemisphere.

The general trend for global temperature increase leads to permafrost thawing. Global warming is currently most pronounced in the Arctic, twice faster than global average, leading to up to $0.7^{\circ} \mathrm{C} /$ decade air and $1.0^{\circ} \mathrm{C} /$ decade soil temperature increase [14]. This leads to permafrost thawing resulting in ground deformation, among other things. During the last century, permafrost regions shrunk by ca. $10 \%$, and each $1{ }^{\circ} \mathrm{C}$ of warming leads to loss of ca. 5.8 million $\mathrm{km}^{2}$. Permafrost also exists in 3.56 million $\mathrm{km}^{2}$ of alpine regions, where it's thawing leads to rock and ice falls, landslides, and floods. Even if permafrost still has a negative temperature, its bearing capacity could be significantly reduced.

To protect constructions and buildings from damage caused by underlying permafrost degradation (for $80 \%$ of those in Russia, hard frozen soil is critical for foundation), different methods are used currently, but those are becoming insufficient at ambient conditions change (thermosyphons, screens) or too expensive (fossil fuel driven refrigerators). Despite long experience of these methods implementation, analysis of best practices and cost effectiveness is still missing. This leads, particularly, to inappropriate 
methods application. E.g., thermosyphons have been suggested originally to maintain soil frozen in depth, under foundation pillars, but those are widely used now where near-surface freezing is needed.

The importance of soil state monitoring is also increasing to prevent disasters, but it is rather expensive across vast unpopulated areas. Nowadays, damage to property caused by permafrost degradation in Russia is measured in $\$ 100 \mathrm{M}^{\prime}$ s yearly [5, 6]. While, even in monetary terms, harm to nature can be orders of magnitude higher (recent $21,000 \mathrm{t}$ diesel fuel spill in Norilsk from a reservoir costing $\$ 300 \mathrm{k}$ led to $\$ 15 \mathrm{M}$ direct losses and $\$ 3 \mathrm{~B}$ environmental damage reimbursement)! All this makes new and costeffective approaches for permafrost thermal stabilization highly demanded.

We have earlier devised a concept combining passive shielding of solar radiation and precipitation and active cooling of the soil by solar-powered heat pump [7, 8]. Assuming solar power generation efficiency to be $15 \%$ and power-to-chill efficiency to be 3.3, overall cooling effect is about a half of the solar irradiation, in addition to the latter being completely rejected from the soil surface. Unlike thermosyphon based systems [9] buried to ca. $10 \mathrm{~m}$, we suggest cooling the near surface layer and, therfore, prevent the heat penetration in depth, significantly reducing the active layer thickness to the ground probes position (first decimeters). These shallow ground probes could be highly demanded in mountainous areas, particularly, to prevent land slides. A significant thermal inertia of the soil resolves of the main problem of the alternative energy - the need to maintain a balance of intermittent generation and priority consumption - here energy can be used as it is generated without special storage devices. Greenhouse gases, chemical, and biological pollution [10] coming from the near-surface soil levels mainly is also prevented in this way. Such distributed solar powered systems are well suited for critical infratrucure protection [11]. Presence of an autonomous power source provides possibilities for thorough monitoring of soil and protected objects in general.

We have performed an experimental proof of this concept, particularly near-surface heat shielding layer maintainance possibility, and hereby present the obtained results.

\section{Experimental Site and Setup}

\subsection{General layout}

The experimental site consisted of the reference plot for soil temperatures and the experimental setup (Figure 1). The latter consisted of the sand prism $(2.5 \times 5.5 \mathrm{~m}$ footprint, $1.1 \mathrm{~m}$ height, 1:1 rate of the side slope) with buried temperature sensors and cooling ground probes $(20 \mathrm{~cm}$ below sand surface at sides and top) and $100 \mathrm{~mm}$ extruded polystirol foam heat insulation $(0.033 \mathrm{~W} /(\mathrm{m} \cdot \mathrm{K}))$ at the bottom and end faces, south end face was additionally covered with Al-foiled LDPE foam (5 $\mathrm{mm}$ thick).

\subsection{Electric subsystem}

Solar panels arrays were placed ca. $40 \mathrm{~cm}$ above sand surface: at $\mathrm{E}$ and $\mathrm{W}$ faces at $45^{\circ}$ tilt, the top array was had just $2^{\circ}$ tilt to $S$. Different types of solar modules were used: flexible mono-Si (1 kW, E side), rollable CIGS (1 kW, top), and framed poly-Si $(0.9 \mathrm{~kW}$, W side). Each array had a separate MPPT tracker (Photon-150-50, A-electronica) coupled to a $2.4 \mathrm{kWh} \mathrm{Li:FePO} 4$ battery (12-200, SunStonePower). Such array daily output reached $15 \mathrm{kWh}$. A $5 \mathrm{~kW}$ solar hybrid inverter (Progress-12-5000-Hybrid, A-electronica) was used to power the heat pump connected via remote controlled solid state relay (80 A) and a soft-start module (SSR-150WA) to damp current at compressor start. 


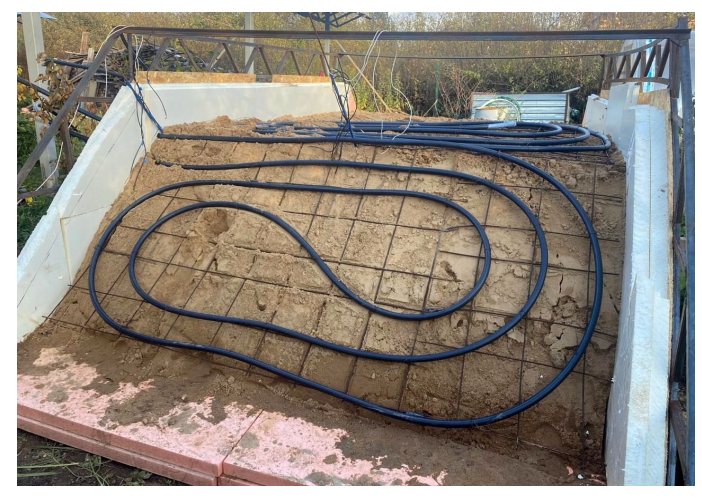

(a)

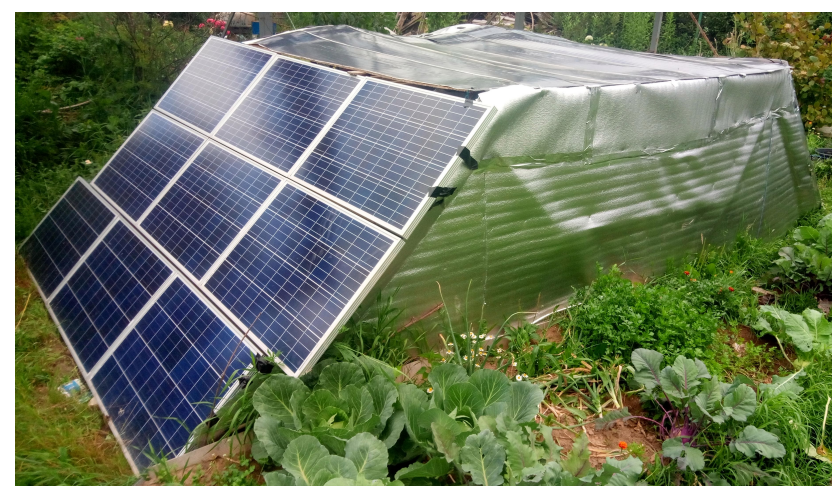

(b)

Figure 1. General view of the experimental setup at construction (a) and operation (b).

\subsection{Heat transfer subsystem}

A $7.8 \mathrm{~kW}_{\mathrm{t}}$ ground-water heat pump (Access-7, EnergyLex) with a nominal of COP 4.3 (or EER 3.3 for cooling) was cooling the ground probes (standard LDPE pipe $25 \mathrm{~mm}$ ) filled with $50 \%$ water solution of ethylene glycol to $-9^{\circ} \mathrm{C}$ return $(18 \mathrm{~L} / \mathrm{min})$ at start-stop regime. There were 4 loops of ground probes (each $20 \mathrm{~m}$ long, with nominal spacing of $20 \mathrm{~cm}$ ): 1 per side and 2 on top. The heat was derived to the $60 \mathrm{~m}^{2}$ floor heating system with return temperature of $+35^{\circ} \mathrm{C}(7 \mathrm{~L} / \mathrm{min})$. The heated house was chilled to $+22^{\circ} \mathrm{C}$ by $8 \mathrm{~kW}_{\mathrm{t}}$ air conditioner.

Heat pump energy efficiency rate (EER) for cooling depends on temperature difference between cold and hot contours. The easiest option for us was to implement a heat sink demanding $50 \mathrm{~K}$ difference between mean temperatures in cold and hot contours. That could be reduced significantly (and so EER increased) if water and soil that does not need thermal stabilization were used. Such heat sinks could normally be found on practice.

\subsection{Data acquisition subsystem}

Data acquisition has been performed using Arduino Due and Uno boards. We have been monitoring soil temperatures in 3 lines at $0,6.7,13.5,27,54$, and $98 \mathrm{~cm}$ below sand surface in the prism and in one reference line outside the setup (sensors at standard 20, $40,80 \mathrm{~cm}$ depths were also added there), between and along ground probes, at the inlets and outlets of the heat pump (separate for each ground loop), air between solar panels and sand prism, and ambient air. Prior to installation, all waterproof DS18B20 temperature sensors were calibrated in an ice bath. We have also been measuring heat fluxes at soil and ground probes surface, water flow in heat pump contours, sand moisture, solar irradiation at prism sides and top, and electric power consumed by the heat pump.

\subsection{Ambient conditions}

We have performed the experiment outside the permafrost regions (N55.1 $\left.{ }^{\circ} ; \mathrm{E} 36.6^{\circ}\right)$. However, this means even harder conditions for the thermal stabilization system since warmer air and no permafrost underlying. These all provided higher thermal loads and lower energy output from solar panels. The reference climatic data are provided in Table 1.

We also used sand as a soil, while it is the second hardest (after gravel and rocks) to keep frozen (has thick active layer). While the turf upper soil layer widely abundant in permafrost regions forms the thinnest active layer and, being almost black, is the most 
sensitive to direct solar irradiation (if surface vegetation is damaged or removed). So, the soil environment also ensured harder conditions for our tests than expected naturally in most cases.

Table 1. Climatic data for the experimental site.

\begin{tabular}{|c|c|c|c|c|c|c|c|c|c|}
\hline \multirow{2}{*}{$\underset{\sum}{\stackrel{5}{\leftrightarrows}}$} & \multirow{2}{*}{$\begin{array}{l}\text { Solar irradiation. } \\
\mathbf{k W h} /\left(\mathbf{m}^{2 *} \text { day), }\right. \\
\text { (averaged } \mathrm{W} / \mathbf{m}^{2} \text { ) }\end{array}$} & \multirow{2}{*}{$\begin{array}{l}\text { Mean air } \\
\text { temp., }{ }^{\circ} \mathrm{C}\end{array}$} & \multirow{2}{*}{$\begin{array}{l}\text { Mean wind } \\
\text { speed, m/s }\end{array}$} & \multirow{2}{*}{$\begin{array}{c}\text { Snow } \\
\text { layer, cm }\end{array}$} & \multicolumn{5}{|c|}{ Soil temperature at depths, ${ }^{\circ} \mathrm{C}$} \\
\hline & & & & & $\begin{array}{l}20 \\
\mathrm{~cm}\end{array}$ & $\begin{array}{l}40 \\
\mathrm{~cm}\end{array}$ & $\begin{array}{r}80 \\
\mathrm{~cm}\end{array}$ & $\begin{array}{l}160 \\
\mathrm{~cm}\end{array}$ & $\begin{array}{l}320 \\
\mathrm{~cm}\end{array}$ \\
\hline 1 & $0.679(28.3)$ & -8.4 & 3.30 & 28.03 & 0.54 & 1.12 & 2.16 & 2.94 & 4.30 \\
\hline 2 & $1.421(59.2)$ & -2.0 & 3.30 & 38.04 & -0.81 & 0.01 & 1.22 & 2.00 & 3.26 \\
\hline 3 & $2.69(112.0)$ & 0.0 & 3.30 & 44.42 & -0.18 & -0.01 & 0.99 & 1.60 & 2.68 \\
\hline 4 & $3.871(161.3)$ & 7.4 & 3.20 & 0.00 & 3.68 & 3.00 & 2.50 & 2.24 & 2.64 \\
\hline 5 & $5.22(217.5)$ & 16.2 & 3.10 & 0.00 & 15.28 & 13.88 & 11.21 & 9.47 & 7.41 \\
\hline 6 & $5.441(226.7)$ & 19.5 & 2.90 & 0.00 & 18.24 & 17.30 & 14.93 & 13.26 & 11.00 \\
\hline 7 & $5.28(220.0)$ & 16.9 & 2.80 & 0.00 & 20.75 & 19.71 & 17.54 & 16.06 & 13.84 \\
\hline 8 & 4.31 (179.6) & 16.3 & 3.00 & 0.00 & 19.54 & 19.05 & 17.74 & 16.78 & 15.10 \\
\hline 9 & $2.731(113.8)$ & 12.1 & 3.30 & 0.00 & 14.00 & 14.19 & 14.25 & 14.20 & 13.83 \\
\hline 10 & $1.57(65.4)$ & 8.6 & 3.30 & 0.00 & 8.93 & 9.65 & 10.80 & 11.39 & 11.87 \\
\hline 11 & 0.799 (33.3) & 0.7 & 3.10 & 0.57 & 3.61 & 4.46 & 6.10 & 7.10 & 8.61 \\
\hline 12 & $0.521(21.70)$ & 0.2 & 3.20 & 20.20 & 0.09 & 1.37 & 3.05 & 4.06 & 5.94 \\
\hline
\end{tabular}

\subsection{Numerical modeling}

We have calculated our experimental setup thermal state according to its actual layout using the same approaches as in [8] to evaluate the numerical and experimental results match. The modeling was performed using Frost-3D Multi-Core GPU software (https://frost3d.ru/eng/) which has been specially developed for permafrost soil calculations, its results validity has been verified by analytical solutions [12] and practical applications, compared to the most popular FEM packages [13], and conformity to relevant national and corporate construction regulations certified.

\section{Results}

First, we have performed a numerical modeling for our experimental setup layout and ambient conditions to see if it is capable of maintaining soil frozen. The results have shown sand would be thawed slightly below ground probes level but frozen core would still exist in the embankment. This modeling allowed us to confirm chosen electric and cooling capacities were sufficient.

\subsection{Thermal measurements}

First, we have performed a numerical modeling for our experimental setup layout and ambient conditions to see if it is capable of maintaining soil frozen. The results have shown sand would be thawed slightly below ground probes level but frozen core would still exist in the embankment. This modeling allowed us to confirm chosen electric and cooling capacities were sufficient.

An example of experimental data is presented in Figure 2. Temperature rise in the beginning of this dataset corresponds to the circulation pump failure. One can see counter phase oscillations in surface and in depth temperatures caused by cooling output increase at high solar irradiation when the heat pump was able to work at maximum performance. There is also about a half-day time lag for this depth, since weaker night heat wave reaches the ground probes level once those are cooled to the maximum extent, and in reverse at night. The ability of comparatively fast (about 3 days) recovery to steady state indicates a fair cooling capacity reserve of the system. 


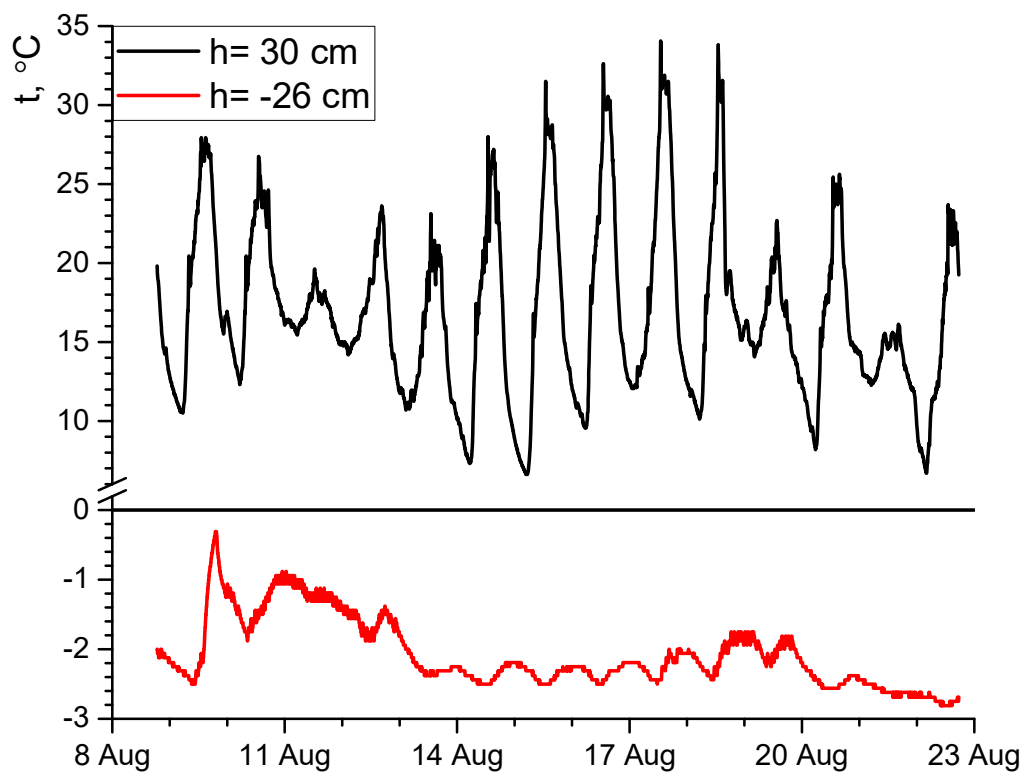

Figure 2. Recorded temperatures of the air under solar panels $(30 \mathrm{~cm})$ and at $26 \mathrm{~cm}$ depth in August 2021.

Peak heat flux through the wall of the ground probe pipe reached $190 \mathrm{~W} / \mathrm{m}^{2}$. Its time averaged value depended on weather (heat pump duty cycle needed to keep the heat carrier in the ground loop cool enough) and power available from the solar panels and battery, it reached $110 \mathrm{~W} / \mathrm{m}^{2}$ in the hottest weather. Assuming the temperature difference through the wall to be about $5 \mathrm{~K}$, the peak and maximum average heat exchange rates could be evaluated as 38 and $22 \mathrm{~W} /\left(\mathrm{m}^{2} \mathrm{~K}\right)$, correspondingly.

Temperature rise in the lower part of the experimental setup (Figure 3 ) is caused by non-ideal heat insulation of the bottom from the warm ground and heat sink from the edges. Since the heat shielding layer has always stayed frozen, it would not let heat in if there was permafrost below.

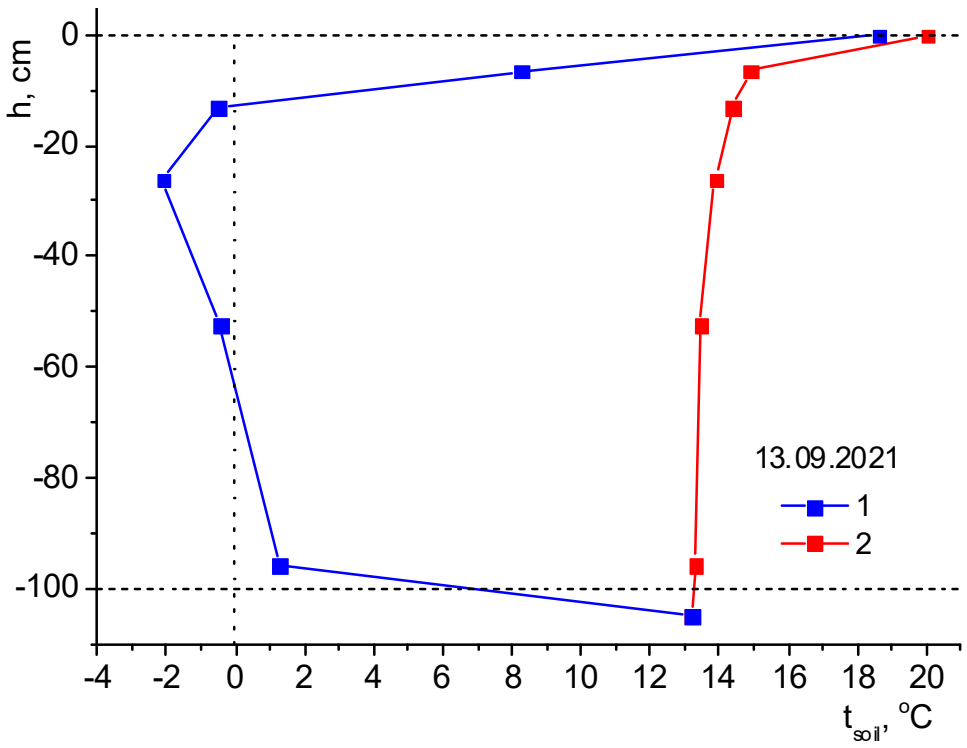

Figure 3. Soil temperature profile at experimental and reference plots $(1-$ experimental and 2 reference sites; dashed line at $-100 \mathrm{~cm}$ depth shows the upper edge of the heat insulation layer) 
The Figure 4 shows that the heat flux at the ground surface of the experimental plot (solar radiation shielded) strongly correlates with the air temperature. While at the reference plot it has higher amplitude obviously caused by solar irradiation, even though the heat flux sensor is hidden under grass and so not irradiated directly. This figure shows how important it is to take solar irradiation into account in numerical calculations. In the autumn and spring, particularly, when convective heat flux is reduced due to small difference between air and soil surface temperatures. Reference soil surface at night is warmer than air, so the heat flux is reversed; while at the experimental site it is reversed only at negative air temperatures at night.

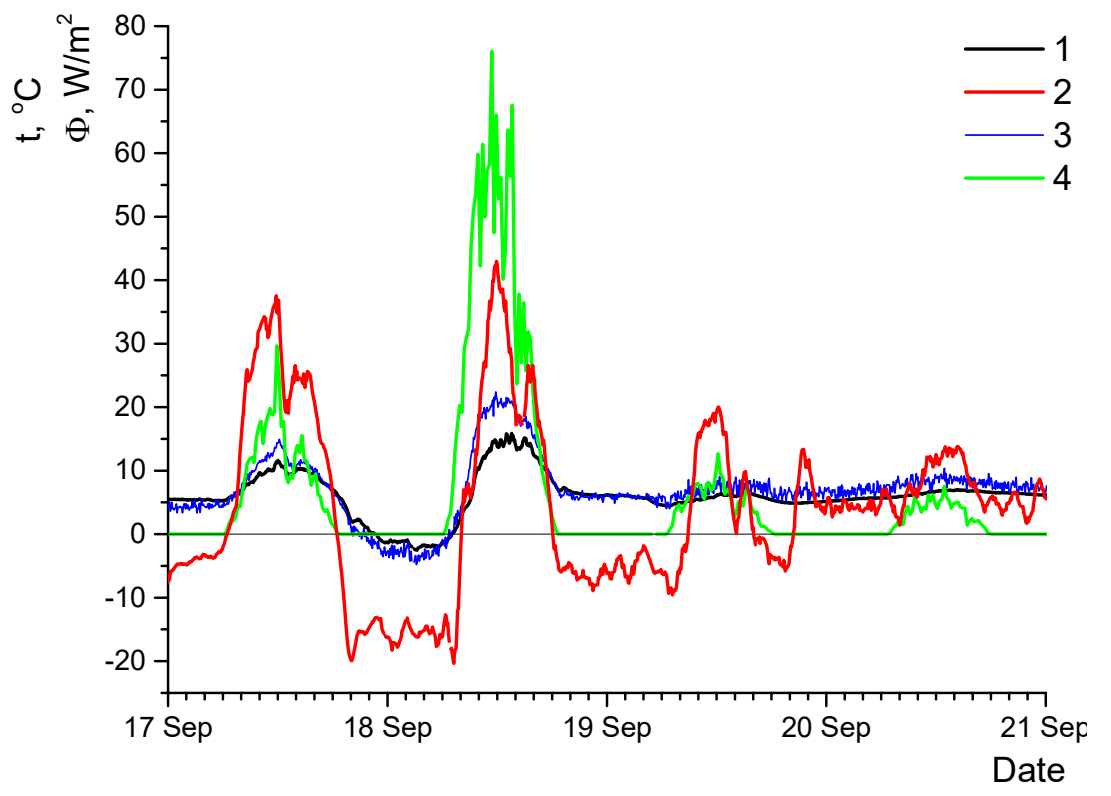

Figure 4. Heat fluxes to the ground and their dependence on meteo data ( 1 - air temperature; heat fluxes $\Phi: 2$ - at the reference plot and 3 - at the experimental site at soil surface, 4 - solar irradiation at horizontal surface (divided by 10))

\subsection{Technical issues}

Failures of the system happened due to high start currents (resolved by soft-start module); circulation pump burnt due to condensate filling the connection box completely (resolved thermal insulation of the pump outer surfaces); MPPT controller fire during hot weather; compressor knocking due to solar inverter frequency modulation failure; DAQ failures after thunderstorms. Since the pipes volume is high, the system needs quite large buffer tanks to damp pressure fluctuations of ethylene glycol reach heat carrier.

We observed no sand surface drying as a result as water vapors condensation on it being rather cool. Keeping soil wet at precipitation rejection is important since its thermophysical properties are strongly dependent on water content. October.

The house where the heat was diverted to did not need other heating till late

\subsection{System cost}

Main system components retail and bulk market prices are listed in Table 2. We suggest that retail price is more or less equal to bulk price plus associated assembly and mounting expenses. For remote areas, logistics might be a significant part of overall project cost, so it is not considered here; just an idea of specific mass for the components is given for basic evaluations. One can see solar panels give the main input in mass. We have not been considering light flexible ones since those are not suitable to withstand 
harsh weather conditions and would need some holding carcass anyway, so considered those certified for $-40^{\circ} \mathrm{C}$. The inverter power matches solar panels power and takes into account its nameplate capacity should be 2.5 -fold of the heat pump compressor drive to avoid collapse at start. Noteworthy, solar panels have been showing $25 \%$ and heat pumps $-10 \%$ price reduction in long-term (negative CAGR). Other technologies for comparison are shown at the bottom of the table.

Table 3. Method implementation cost estimates

\begin{tabular}{|c|c|c|c|c|}
\hline & & Retail price, $\$$ & Bulk price, $\$$ & Mass, kg \\
\hline Solar panels & per $\mathrm{kW}$ & 550 & 300 & 50 \\
\hline $0.15 \mathrm{~kW} / \mathrm{m}^{2}$ & per $\mathrm{m}^{2}$ & 82.5 & 45 & 7.5 \\
\hline Solar inverter+MPPT & per $\mathrm{kW}$ & 90 & 40 & 2 \\
\hline $0.15 \mathrm{~kW} / \mathrm{m}^{2}$ & per $\mathrm{m}^{2}$ & 13.5 & 6 & 0.3 \\
\hline Heat pump & per $\mathrm{kW}^{1}$ & 468 & 130 & 5 \\
\hline $0.1 \mathrm{~kW} / \mathrm{m}^{2}$ & per $\mathrm{m}^{2}$ & 46.8 & 13 & 0.5 \\
\hline Ground probes+coolant & per $\mathrm{m}$ & 0.5 & 0.2 & 0.2 \\
\hline $5 \mathrm{~m} / \mathrm{m}^{2}$ & per $\mathrm{m}^{2}$ & 2.5 & 1 & 1 \\
\hline Energy storage & per $\mathrm{kWh}$ & 400 & 150 & 4 \\
\hline $0.12 \mathrm{kWh} / \mathrm{m}^{2}$ & per $\mathrm{m}^{2}$ & 48 & 18 & 0.48 \\
\hline Total & per $\mathrm{m}^{2}$ & 193.3 & 83 & 9.78 \\
\hline Thermosyphon & per $\mathrm{m}^{2}$ & $176^{2}$ & 110 & 16 \\
\hline Solar powered chiller [9] & per $\mathrm{m}^{2}$ & - & 125 & - \\
\hline
\end{tabular}

${ }^{1}$ per cooing capacity, for geothermal and water-air heat pumps heating capacity is usually specified, to estimate cooling capacity, electric capacity should be subtracted from that.

2 bulk price and mounting cost.

\section{Discussion}

\subsection{System layout}

Start-stop regime for a heat pump is unfavorable due to high loads on compressor, electric system, and battery cycling. It is much better to use the inverter technology (frequency conversion) for soft start and smooth output control to match solar panels power. In inverter technology, $A C$ is converted to $D C$, and then back to $A C$ at variable frequency. And solar inverter makes DC to AC conversion before that. It is reasonable to avoid such multiple conversions to reduce system cost and increase its reliability supplying DC current from solar panels just before the last DC/AC conversion. Similar task exists for solar powered irrigation, so recently solar pump inverters have become commercially available. Those are fed from solar panels, have built-in MPPT-tracker and provide $\mathrm{AC}$ at the output so that the frequency matches the actual power supply.

Moreover, using DC-driven compressors might be even more reasonable, particularly with brushless (BLDC) drives widely used in electric transport now. Such BLDC driven cooling units are used for the car fridges, but usually have small power and poor performance. This approach is also used in solar-driven water pumps. Such drives coupled with magnetocaloric heat pumps [14] could significantly reduce balanceof-system cost by eliminating the nameplate capacity reserve needed to start a traditional heat pump compressor.

For large scale systems and remote areas, rotary refrigerators (turbo expanders) could be considered since having significantly lower specific mass and volume (ca. 4fold while being twice more expensive per $\mathrm{W}_{\mathrm{t}}$ ) that considerably affects logistics expenses to remote regions. For the same reason we suggest using solar vaccuum tube collectors with absorption heat pumps might be undesirable even though potentially having higher solar energy to chill conversion efficiency. 
For ground probes assembly, two approaches are most suitable in general. The first one is to lay those on the cleaned surface and put a ground layer on top. This method is most suitable for the road embankments. It can be implemented regardless of substrate state: actual thawed layer thickness, rocks, etc. The disadvantage is need for at least 0.25 $\mathrm{m}^{3} / \mathrm{m}^{2}$ of soil (depending on compression rate) to be laid; workforce for ground probes deployment. The second is use cable laying machines that are capable to deploy the probes in a highly productive mode. For that, the soil should be thawed at least $10 \mathrm{~cm}$ deeper than projected probes. It is not so meaningful in this case if the vegetation is damaged since the soil will be shielded by solar panels.

\subsection{Method applicability}

A degree-days concept is often used for basic thermal balance evaluations that reflects temperature gradients correlating with the convective flux. In Table 3 and Figure 5 , we present data for comparison of conditions in these terms at our test site and those used for calculations in [8]. Here, we are considering positive degree-days only, while negative are significant, too. For colder winters in permafrost areas, these negative degree-days should lead to better soil cooling, particularly, since almost no snow is accumulated under solar panels, so putting our test site in even less favorable conditions for thermal stabilization. We derived a climatic performance indicator to evaluate solar powered cooling capability of thermal stabilization as a ratio of solar irradiation to degree-days during warm season. The higher the value it has, the easier conditions for our method are. Figure 5 shows the method is potentially available throughout the Russian territory.

Table 3. Ambient conditions comparison (warm season - positive degree-days at no snow).

\begin{tabular}{ccccccccc}
\hline Month & \multicolumn{3}{c}{ Positive degree-days per month } & \multicolumn{5}{c}{ Solar irradiation at horizontal surface } \\
& & \multicolumn{2}{c}{$\mathrm{kWh} /\left(\mathrm{m}^{2 *}\right.$ mon) } & \\
& Our site & Norilsk & Yakutsk & Chita & Our site & Norilsk & Yakutsk & Chita \\
\hline 1 & -260 & -812 & -1132 & -843 & 21.05 & 0.31 & 8.06. & 33.48 \\
2 & -56 & -678 & -983 & -501 & 39.79 & 8.68 & 22.68 & 59.92 \\
3 & 0 & -595 & -477 & -205 & 83.39 & 42.16 & 86.18 & 112.8 \\
4 & 222 & -432 & -63 & 144 & 116.1 & 97.2 & 134.1 & 145.8 \\
5 & 502 & -164 & 295 & 304 & 161.8 & 146.9 & 163.4 & 180.1 \\
6 & 585 & 123 & 483 & 558 & 163.2 & 155.1 & 175.8 & 184.2 \\
7 & 524 & 394 & 698 & 593 & 163.7 & 152.8 & 166.5 & 165.2 \\
8 & 505 & 310 & 539 & 568 & 133.6 & 102.6 & 132.1 & 138.6 \\
9 & 363 & 51 & 114 & 219 & 81.9 & 53.4 & 72.3 & 105.9 \\
10 & 267 & -329 & -158 & 56 & 48.67 & 19.53 & 37.82 & 73.16 \\
11 & 21 & -627 & -795 & -441 & 23.97 & 1.8 & 12.6 & 39.3 \\
12 & 6 & -772 & -1119 & -725 & 16.15 & 0 & 4.34 & 25.73 \\
\hline Warm & & & & & & & \\
season & 2968 & 878 & 2128 & 2440 & 0.2931 & 0.5291 & 0.3341 & 0.4071 \\
(year) & $(2678)$ & $(-3531)$ & $(-2599)$ & $(-275)$ & & & & \\
total & & & & & & & & \\
\hline
\end{tabular}

${ }^{1}$ sum of averaged solar irradiation during warm season divided by sum of degree-days during warm season; higher the value, easier conditions for solar-powered thermal stabilization.

To better evaluate the applicability of the method to the local conditions, the system layout should be considered too. First, the product of solar energy conversion efficiency and heat pump EER gives the overall solar to chill conversion efficiency, which can vary significantly, that gives, after multiplication by the climatic performance indicator, the specific system performance indicator. Second, this parameter could also be improved by increasing solar converters area over protected (thermally stabilized). But we also 
suggest considering such power increase using wind, particularly for coastal areas. It is also known wind power output has negative correlation with solar, being complementary sources [15], which makes energy flow to power the heat pump more stable. Such additional power increases the numerator, so leads to the overall performance indicator rise. Another way to increase the resulting performance is to place converters vertically, since the incident solar radiation flux will be higher in high altitude regions, or at optimal angles on the wall, where applicable.

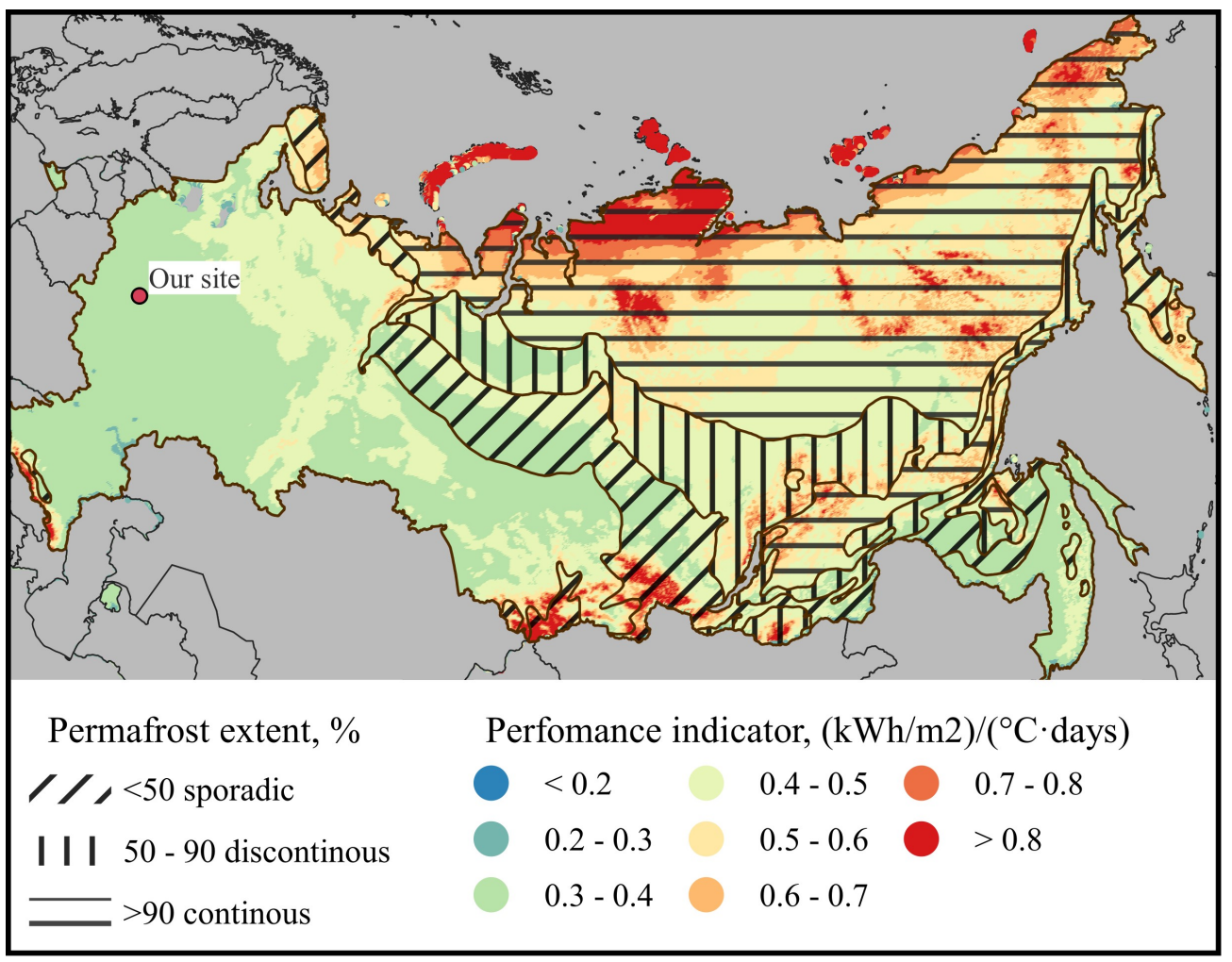

Figure 5. The climatic performance indicator map showing the method applicability (values above 0.3 at equal are of solar power converters and protected area) according to climatic data (not normalized by system layout).

The next step is to pilot the project in relevant environment with industrial heavyduty equipment, casing, and scale. System control algorithms should also be developed to be synchronized with weather forecast at different time scale; cooling capacity redistribution according to actual thermal loads.

We suggest the technology could also be used to prevent the development of thermokarst, gas emission craters, and landslides; greenhouse gases, chemical, and biological pollution from the upper thawing layers at least in the area of human activities; permafrost restoration after wildfires; and protection against coastal erosion [16]. The most important market feature of the proposed technology is that it can generate revenue through the sale of thermal energy removed from the ground (that could be used, for example, in greenhouses significantly advancing possibilities for horticulture in remote Arctic settlements), and, to a lesser extent, excess electricity (more important is not the amount of energy supplied, but its availability throughout the protected object, for example, for control and monitoring systems).

\section{Conclusions}

We have experimentally proven the concept suggesting that solar irradiation to chill conversion is capable of maintaining soil frozen, even at warmer and less sunny 
conditions outside the permafrost areas. The cheapest off-the-shelf equipment was used for this. Even though it could be specially optimized for the method implementation, for the moment, it is important the system could be scaled up to virtually any size.

Technical results when using the proposed technology significantly exceed analogues at a comparable cost and specific mass; it could help to reduce environmental risks insurance fees significantly. The main feature of this technology is blocking heat penetration in depth, so preserving a thick frozen soil layer all year round. This approach is more efficient for surface objects than widely used thermosyphons designed for pillars base freezing in depth.

\section{Patents}

Authors are holding a patent RU 2748086 C1 (ePCT application RU2021/050325) for the method being proven.

Author Contributions: Conceptualization, methodology, validation, formal analysis, investigation, E.S.S., T.V.S. and E.Y.L.; resources and data curation, E.S.S. and E.Y.L.; writing original draft preparation, E.Y.L.; writing - review and editing, E.S.S. and T.V.S.; visualization, E.S.S. and E.Y.L.; supervision and project administration, E.Y.L.; funding acquisition, E.S.S. All authors have read and agreed to the published version of the manuscript.

Funding: Work of E.Y.L has been supported by the Russian Ministry of Science and Higher Education (state assignment No. 0705-2020-0046). Major hardware has been purchased using funds granted to E.S.S. by the Russian Foundation for Assistance to Small Innovative Enterprises (agreement No.15718GU/2020) and the development is continued under agreement No. 4341GS1/70539.

Data Availability Statement: Main real-time data on temperature measurements are available at http://thingspeak.com/channels/1471266.

Acknowledgments: Simmakers Ltd. has provided E.S.S. a free remote access to the Frost-3D package. Data acquisition and analysis were performed using the equipment of the «Beam-M» facility (Bauman Moscow State Technical University). Authors are extremely grateful to D.D. Skorik and R.A. Gerasimova for their help with the experimental site construction and maintenance.

Conflicts of Interest: The authors declare no conflict of interest, except those could potentially arise at self-proving of the patented method. The funders had no role in the design of the study, in the collection, analyses, or interpretation of data; in the writing of the manuscript, or in the decision to publish the results.

\section{References}

1. Chen, L.; Yu, W.; Lu, Y.; Liu, W. Numerical simulation on the performance of thermosyphon adopted to mitigate thaw settlement of embankment in sandy permafrost zone. Appl. Thermal Eng. 2018, 128, 1624-1633. doi: 10.1016/j.applthermaleng.2017.09.130.

2. Post, E.; Alley, R. B.; Christensen, T. R.; Macias-Fauria, M.; Forbes, B. C.; Gooseff, M. N.; Iler, A.; Kerby, J. T.; Laidre, K. L.; Mann, M. E.; Olofsson, J.; Stroeve, J. C.; Ulmer, F.; Virginia, R. A.; Wang, M. The polar regions in a $2^{\circ} \mathrm{C}$ warmer world. Sci. Advances 2019, 5 (12), eaaw9883. doi: 10.1126/sciadv.aaw9883.

3. Van Huissteden, J. Thawing permafrost: Permafrost carbon in a warming arctic. 2020; p 1-508. doi: 10.1007/978-3-030-31379-1.

4. $\quad$ Biskaborn, B. K.; Smith, S. L.; Noetzli, J.; Matthes, H.; Vieira, G.; Streletskiy, D. A.; Schoeneich, P.; Romanovsky, V. E.; Lewkowicz, A. G.; Abramov, A.; Allard, M.; Boike, J.; Cable, W. L.; Christiansen, H. H.; Delaloye, R.; Diekmann, B.; Drozdov, D.; Etzelmüller, B.; Grosse, G.; Guglielmin, M.; Ingeman-Nielsen, T.; Isaksen, K.; Ishikawa, M.; Johansson, M.; Johannsson, H.; Joo, A.; Kaverin, D.; Kholodov, A.; Konstantinov, P.; Kröger, T.; Lambiel, C.; Lanckman, J.-P.; Luo, D.; Malkova, G.; Meiklejohn, I.; Moskalenko, N.; Oliva, M.; Phillips, M.; Ramos, M.; Sannel, A. B. K.; Sergeev, D.; Seybold, C.; Skryabin, P.; Vasiliev, A.; Wu, Q.; Yoshikawa, K.; Zheleznyak, M.; Lantuit, H. Permafrost is warming at a global scale. Nat. Comm. 2019,10 (1), 264. doi: 10.1038/s41467-018-08240-4.

5. Badina, S. V. Estimation of the value of buildings and structures in the context of permafrost degradation: The case of the Russian Arctic. Polar Sci. 2021, 29, 100730. doi: 10.1016/j.polar.2021.100730.

6. Streletskiy, D. A.; Suter, L. J.; Shiklomanov, N. I.; Porfiriev, B. N.; Eliseev, D. O. Assessment of climate change impacts on buildings, structures and infrastructure in the Russian regions on permafrost. Environmental Res. Lett. 2019, 14 (2), 025003. doi: 10.1088/1748-9326/aaf5e6. 
7. Loktionov, E. Y.; Sharaborova, E. S.; Asanov, I. M. Prospective Sites for Solar-Powered Permafrost Stabilization Systems Integration in Russian Railways, 2019. In 8th International Conference on Renewable Energy Research and Applications (ICRERA), Brasov, Romania, 2019; IEEE: Brasov, Romania, 2019; p 8996544. doi: 10.1109/ICRERA47325.2019.8996544.

8. Loktionov, E. Y.; Sharaborova, E. S.; Shepitko, T. V. A Sustainable Concept for Permafrost Thermal Stabilization. Sustain. Energy Technol. Assessments 2022, under review after revision. https://arxiv.org/abs/2108.10138.

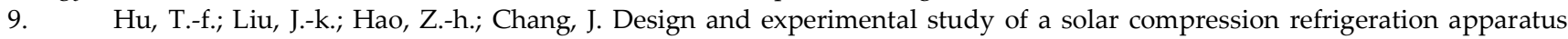
(SCRA) for embankment engineering in permafrost regions. Transport. Geotechn. 2020, 22, 100311. doi: 10.1016/j.trgeo.2019.100311.

10. Miner, K. R.; D'Andrilli, J.; Mackelprang, R.; Edwards, A.; Malaska, M. J.; Waldrop, M. P.; Miller, C. E. Emergent biogeochemical risks from Arctic permafrost degradation. Nat. Climate Change 2021, 11 (10), 809-819. doi: 10.1038/s41558-021-01162y.

11. Asanov, I. M.; Loktionov, E. Y. Possible benefits from PV modules integration in railroad linear structures. Renew. Energy Focus 2018, 25, 1-3. doi: 10.1016/j.ref.2018.02.003.

12. Dauzhenka, T. A.; Gishkeluk, I. A. Consistency of the Douglas - Rachford splitting algorithm for the sum of three nonlinear operators: application to the Stefan problem in permafrost soils. Appl. Comput. Math. 2013, 2 (4), 100-108. doi: 10.11648/j.acm.20130204.11.

13. Alekseev, A.; Gribovskii, G.; Vinogradova, S. Comparison of analytical solution of the semi-infinite problem of soil freezing with numerical solutions in various simulation software. IOP Conf. Ser.: Mat. Sci.Eng. 2018, 365, 042059. doi: 10.1088/1757$899 \times / 365 / 4 / 042059$.

14. Johra, H.; Filonenko, K.; Heiselberg, P.; Veje, C.; Dall'Olio, S.; Engelbrecht, K.; Bahl, C. Integration of a magnetocaloric heat pump in an energy flexible residential building. Renew. Energy 2019, 136, 115-126. doi: https://doi.org/10.1016/j.renene.2018.12.102.

15. Solbakken, K.; Babar, B.; Boström, T. Correlation of wind and solar power in high-latitude arctic areas in Northern Norway and Svalbard. Renew. Energy Environ. Sustain. 2016, 1, 42. doi: 10.1051/rees/2016027.

16. Ogorodov, S.; Aleksyutina, D.; Baranskaya, A.; Shabanova, N.; Shilova, O. Coastal Erosion of the Russian Arctic: An Overview. J. Coastal Res. 2020, 95 (sp1), 599-604. doi: 10.2112/SI95-117.1. 